\title{
Clip-with-line traction suture method with adaptation of the mucosal flap in a large transmural defect after submucosal tunneling endoscopic resection of a submucosal tumor at the esophagogastric junction
}

Submucosal tunneling endoscopic resection (STER) [1] is a demanding technique that can potentially lead to serious complications [2,3]. A 51-year-old patient with solid food dysphagia underwent an esophagogastroduodenoscopy, which showed a subepithelial mass just below the esophagogastric junction (EGJ). Endoscopic ultrasound confirmed a well-demarcated $30 \times 24 \mathrm{~mm}$ subepithelial mass attached to the muscularis propria, predominantly hypoechogenic but with some hyperechogenic foci.

STER was performed using a HybridKnife I-Type (Endocut-Q, Setting 2-3-3, Vio 300D; ERBE Elektromedizin, Tübingen, Germany) under low-flow carbon dioxide insufflation ( $\vee$ Video 1 ). A $2-\mathrm{cm}$ longitudinal mucosal access was created in the esophagus, $4 \mathrm{~cm}$ proximal to the EG], and a submucosal tunnel was created until the submucosal lesion was found in the deep posterior muscularis propria layer ( $\mathbf{F i g . 1} \mathbf{a}, \mathbf{b})$. To avoid tumor capsule damage, the muscular layer had to be opened. Owing to the difficult position of the lesion, the scope had to be at maximum retroflexion for deep muscular layer preparation. However, a large mucosal tear was observed, caused by the traction exerted by the scope during the procedure, thus causing a large

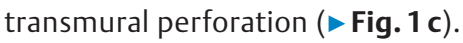

After tumor removal (> Fig.2a), a 16mm hemostatic clip (Lockado-Clip, Microtech Europe, Duesseldorf, Germany) with medical floss was placed in the proximal margin of the mucosal flap. The floss was pulled to lift the mucosal flap upwards to cover the defect. Subsequently the tear was closed by attaching the side margins of the flap to the surrounding mucosa using 20-mm hemostatic clips (Lockado-Clip, Microtech Europe, Duesseldorf, Germany) ( Fig. 2 b, c).

Broad-spectrum antibiotic therapy was given. The following day, an esophagram confirmed no leakage and a liquid

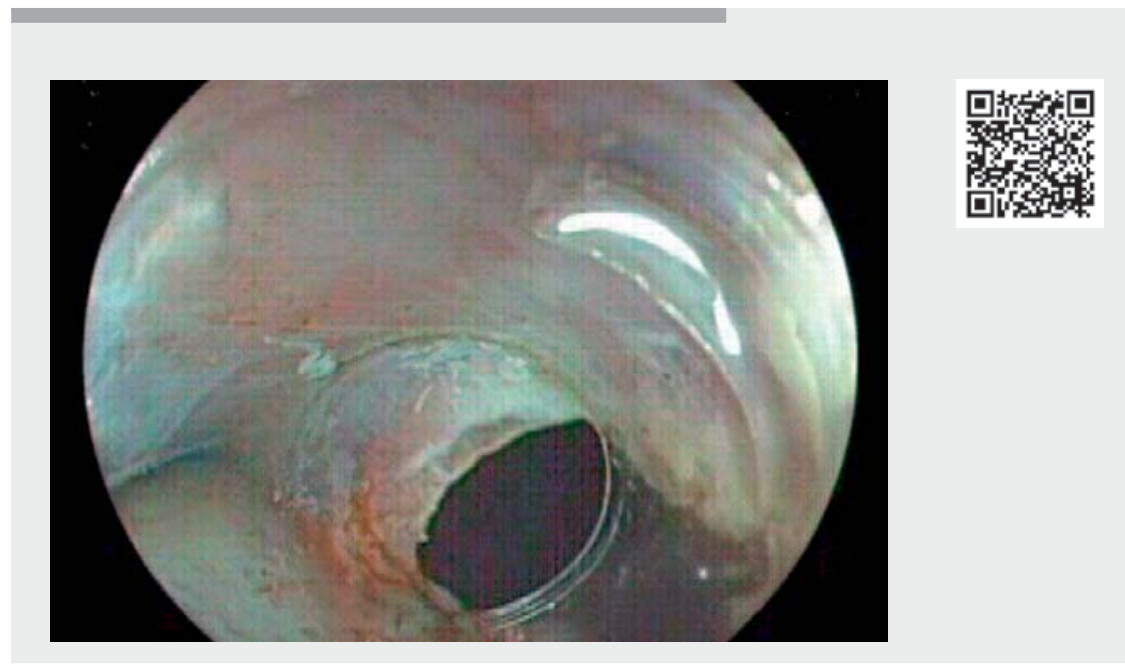

Video 1 Clip-with-line traction suture method with adaptation of the mucosal flap in a large transmural defect after submucosal tunneling endoscopic resection.

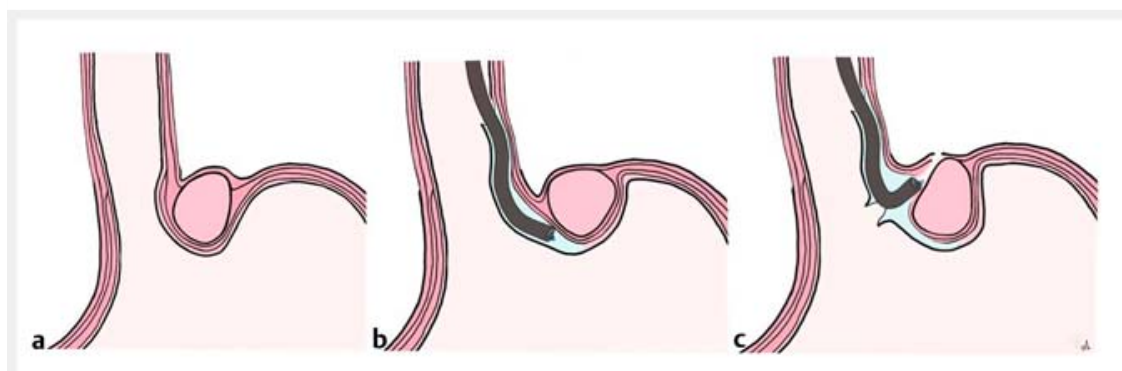

- Fig. 1 Schema of submucosal tunneling endoscopic resection technique. a Submucosal tumor. b Submucosal tunneling. c Muscular layer dissection and evidence of a mucosal tear.

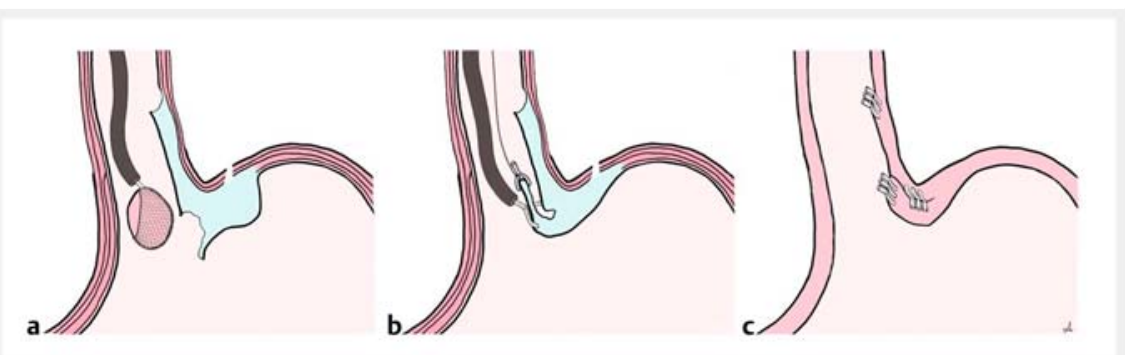

- Fig. 2 Closure of the tear. a Complete resection and tumor removal. b Clip-with-line traction suture method. c Complete defect closure by mucosal flap and tunnel entrance closure. 
diet was started. After follow-up endoscopy on Day 3, the patient received a semi-liquid diet and was then discharged on a regular diet. There were no complications during the follow-up. Histology showed a leiomyoma.

The clip-with-line traction suture method was previously described to align mucosal margins to allow easier defect closure after submucosal dissection [4]. In the current case, it was used to close the mucosal flap over the tear.

Endoscopy_UCTN_Code_CPL_1AH_2AJ

\section{Competing interests}

The authors declare that they have no conflict of interest.

The authors

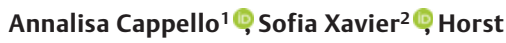
Neuhaus $^{3}$, Torsten Beyna ${ }^{3}$, Christian Gerges ${ }^{3}$

1 AUSL Bologna, Bologna, Italy

2 Hospital Senhora da Oliveira, Guimarães, Portugal

3 Evangelisches Krankenhaus, Düsseldorf, Germany
Corresponding author

\section{Annalisa Cappello, MD}

AUSL Bologna, Department of Gastroenterology and Interventional Endoscopy, Largo Nigrisoli 2, 40133 Bologna (BO), Italy annalisacappello@yahoo.it

\section{References}

[1] Xu MD, Cai MY, Zhou PH et al. Submucosal tunneling endoscopic resection: a new technique for treating upper Gl submucosal tumors originating from the muscularis propria layer (with videos). Gastrointest Endosc 2012; 75: 195-199

[2] Lv XH, Wang CH, Xie Y. Efficacy and safety of submucosal tunneling endoscopic resection for upper gastrointestinal submucosal tumors: a systematic review and meta-analysis. Surg Endosc 2017; 31: 49-63

[3] Chen T, Zhang C, Yao LQ et al. Management of the complications of submucosal tunneling endoscopic resection for upper gastrointestinal submucosal tumors. Endoscopy 2016; 48: 149-155

[4] Wang C, Wang Y, Li Y et al. A clip-with-line traction suture method for closing mucosal defects after endoscopic submucosal dissection. Gastroenterol Res Pract 2021; 2021: 8817726
Bibliography

Endoscopy 2022; 54: E646-E647

DOI 10.1055/a-1731-7268

ISSN 0013-726X

published online 4.2.2022

(C) 2022. Thieme. All rights reserved.

Georg Thieme Verlag KG, Rüdigerstraße 14 , 70469 Stuttgart, Germany

\section{ENDOSCOPY E-VIDEOS}

https://eref.thieme.de/e-videos

口回 Endoscopy E-Videos is an open access online section, 靣: reporting on interesting cases and new techniques in gastroenterological endoscopy. All papers include a high quality video and all contributions are freely accessible online. Processing charges apply (currently EUR 375), discounts and wavers acc. to HINARI are available.

This section has its own submission website at

https://mc.manuscriptcentral.com/e-videos 